\title{
Prevalence of Metabolic Syndrome and Its Risk Factors among Urban Sikh Population of Amritsar
}

\author{
${ }^{1}$ Amrinder Singh, ${ }^{2}$ Shweta Shenoy, ${ }^{3}$ Jaspal Singh Sandhu
}

\begin{abstract}
Metabolic syndrome (MS) refers to a cluster of various interrelated cardiometabolic risk factors that promote the development of atherosclerotic cardiovascular disease (CVD) and type 2 diabetes mellitus (T2DM). South Asians also seem to have a peculiar body phenotype known as South Asian Phenotype, characterized by increased waist circumference, increased waist hip ratio, excessive body fat mass, increased plasma insulin levels and insulin resistance, as well as an atherogenic dyslipidemia, with low levels of HDL cholesterol and increased triglyceride levels. Epidemiologists in India and international agencies such as the world health organization (WHO) have been sounding an alarm on the rapidly rising burden of CVD for the past 15 years. Thus, the primary aim of this study was to identify the prevalence of MS in the Urban Sikh Population of Amritsar by means of a door-to-door survey. A secondary aim was to identify the risk factors for the development of MS. The sample size of 1089 subjects was calculated. This study focused on Urban Sikhs living in Amritsar, Punjab. The overall prevalence of MS in Urban Sikh population of Amritsar was $34.3 \%$ with a higher prevalence among women (41.4\%) compared with men (28.2\%). We also found that the prevalence of MS increases with age in both sexes. We infer that out of 1089 subjects there were only 84 subjects who reported with not a single abnormal component of the MS. The rest 1005 subjects had either one or more component abnormal in them.
\end{abstract}

Keywords: Metabolic syndrome, Prevalence, Cardiovascular disorders, Urban population.

How to cite this article: Singh A, Shenoy S, Sandhu JS. Prevalence of Metabolic Syndrome and Its Risk Factors among Urban Sikh Population of Amritsar. J Postgrad Med Edu Res 2015;49(1):18-25.

\section{Source of support: Nil}

Conflict of interest: None

\section{INTRODUCTION}

Metabolic syndrome (MS) refers to a cluster of various interrelated cardiometabolic risk factors that promote the development of atherosclerotic cardiovascular disease (CVD) and type 2 diabetes mellitus (T2DM). ${ }^{1}$ It is now

\footnotetext{
${ }^{1}$ Assistant Professor, ${ }^{2}$ Associate Professor, ${ }^{3}$ Professor

1-3Department of Sports Medicine and Physiotherapy, Guru Nanak Dev University, Amritsar, Punjab, India
}

Corresponding Author: Amrinder Singh, Assistant Professor Department of Sports Medicine and Physiotherapy, Guru Nanak Dev University, Amritsar, Punjab, India, Phone: 9501114474, e-mail: singhamrinder_30@yahoo.com well known that MS is a risk factor for increased cardiovascular mortality and morbidity. MS is a complex web of metabolic factors that are associated with a two-fold risk of CVD and a five-fold risk of diabetes. Individuals with MS have a 30 to $40 \%$ probability of developing diabetes and/or CVD within 20 years, depending on the number of components present. ${ }^{2}$ Metabolic syndrome is a lifestyle disease and factors contributing to recent changing patterns in metabolic syndrome prevalence in this particular geographic region may provide interesting insights into tackling the ever-rising burden of T2DM and CVD within a wider context of South Asians.

In the United States (US), the prevalence of the MS in the adult population was estimated to be more than $25 \%$. Similarly, the prevalence of MS in 7 European countries was approximately $23 \%$. It was estimated that 20 to $25 \%$ of South Asians have developed MS and many more may be prone to it. ${ }^{3,4}$

Asian Indians have an increased prevalence of coronary heart disease (CHD) and T2DM among all ethnic groups. ${ }^{5,22}$ This Asian Indian or South Asian Paradox refers to the fact that high prevalence of diabetes is seen in people originating from South Asian nations of Bangladesh, India, Nepal, Pakistan and Sri Lanka, despite lower rates of obesity (as defined by conventional body-massindex criteria). ${ }^{2,3}$ Approximately, about one-third of urban South Asians have evidence of the metabolic syndrome. ${ }^{6}$ Moreover, insulin resistance was observed to be there in nearly $30 \%$ of Asian Indian children and adolescents and many exhibit features of metabolic syndrome. ${ }^{7}$

The prevalence of obesity and MS is rapidly increasing in India and other South Asian countries, leading to increased mortality and morbidity due to CVD and T2DM. ${ }^{8,22}$ Since MS and obesity track into adulthood, these clinical entities need to be recognized early in the life-course for effective prevention of T2DM and CVD. ${ }^{9}$

South Asians also seem to have a peculiar body phenotype known as South Asian Phenotype, characterized by increased waist circumference, increased waist hip ratio, excessive body fat mass, increased plasma insulin levels and insulin resistance, as well as an atherogenic dyslipidemia, with low levels of HDL cholesterol and increased triglyceride levels. ${ }^{8,22}$

Unfortunately, representative periodic nationwide data on cardiovascular risk factors for monitoring and surveillance are lacking in India. ${ }^{10,11}$ 
Epidemiologists in India and international agencies such as the world health organization (WHO) have been sounding an alarm on the rapidly rising burden of CVD for the past 15 years. It is estimated that by 2020, CVD will be the largest cause of disability and death in India, with 2.6 million Indians predicted to die due to $\mathrm{CVD} .12,13$

The urban population is very prone to development of cardiovascular diseases with Sidhu et al putting the figure at $20.15 \%{ }^{14}$ Inspite of the predilection of this population to the development of CVD, there has been no epidemiological surveys study in this population.

Thus, the primary aim of this study was to identify the prevalence of metabolic syndrome in the Urban Sikh population of Amritsar by means of a door-to-door survey. A secondary aim was to identify the risk factors for the development of metabolic syndrome.

\section{Definition of Metabolic Syndrome}

The WHO 1999 criteria $^{15}$ require the presence of any one of diabetes mellitus, impaired glucose tolerance, impaired fasting glucose or insulin resistance, And two of the following:

- Blood pressure: $\geq 140 / 90 \mathrm{~mm} \mathrm{Hg}$

- Dyslipidemia: triglycerides (TG): $\geq 150 \mathrm{mg} / \mathrm{dl}$ and highdensity lipoprotein cholesterol (HDL-C) $\geq 40 \mathrm{mg} / \mathrm{dl}$

- Central obesity: waist:hip ratio $>0.90$ (male); $>0.85$ (female), or body mass index $>30 \mathrm{~kg} / \mathrm{m}^{2}$

- Microalbuminuria: urinary albumin excretion ratio $\geq 20 \mu \mathrm{g} / \mathrm{min}$ or albumin:creatinine ratio $\geq 30 \mathrm{mg} / \mathrm{gm}$.

\section{METHODOLOGY}

The sample size of 1089 subjects was calculated. The multi stage cluster randomized sampling was done using the probabilities proportional size (PPS) method. This study focused on Urban Sikhs living in the Amritsar, Punjab, India as they constitute $70 \%$ of the total population of Amritsar according to 2011 census report. The area was arbitrarily divided into five equal zones namely (Z1, Z2, $\mathrm{Z} 3, \mathrm{Z4}$, Z5). Each zone constituted of 13 Censes wards. The list provided the name, age and address of those eligible for voting ( $>18$ years). The fieldwork was completed in a period of 20 months, starting in Jan 2012. The totals of 215 subjects from each zone were randomly selected. In the selection of the family in a particular ward the WHO method of sampling was followed to prevent any nonuniformity in selection of the subjects. A model consent form was constructed to ensure compliance with ICMR guidelines regarding the use of human subjects in research. All protocols and consent documents were reviewed and approved by the Institutional Ethics Committee of Faculty of Sports Medicine and Physiotherapy, Guru Nanak Dev University, Amritsar. The complete detailed Performa of all the family members was filled by the investigator which included number of members in the family, age, educational status, etc. From the list provided one male and one female member were randomly selected. These two family members were requested to fill in the selfdesigned, professionally validated questionnaire.

The fasting blood sample was taken for the analysis of biochemical variables. The blood was analyzed for serum cholesterol, $(\mathrm{CHO})$, serum trigylerides (TG), (High density lipoprotein (HDL), (Low density lipoprotein (LDL), very low density lipoprotein (VLDL). The anthropometric readings were taken namely height, weight, waist (WC) and hip circumference $(\mathrm{HC})$.

\section{STATISTICAL ANALYSIS}

All values given in the text, figures, and tables are represented as mean $\pm \mathrm{SE}$. A one-way analysis of variance (ANOVA) was used to determine significant differences between the EG and CG group. After we had pooled the two intervention groups, Scheffe's test were used to compare relative changes from before to after training between the EG group and CG group. Scheffe's tests were used to test for significant changes within groups from before to after training. The level of significance was set at $p \leq 0.05$. Data analysis was performed using SPSS (version 20.0, SPSS Inc, Chicago, Ill).

\section{RESULTS}

All the statistical analysis was done using Stata 11.2. The association of the categorical variables with outcomes was seen by the Chi-square test. $p$-values less than 0.05 were taken as significant. Unadjusted odd's ratio of relationship of each factor with outcomes was found using binary logistic regression test. Factors, which are significant in univariate analysis, were included in multivariate analysis using multivariable logistic regression test.

\section{Significant Predictors of Metabolic Syndrome}

Table 1 shows overall prevalence of MS in the Urban Sikh population of Amritsar. Table 2 specifies the gender wise mean and standard deviation values of various

Table 1: Prevalence with $95 \%$ confidence interval

\begin{tabular}{llll}
\hline Lifestyle disorder & Total subject population & Frequency & Prevalence in percentage (95\% Cl) \\
\hline Metabolic syndrome & 1089 & 374 & $34.3(31.5,37.1)$ \\
\hline Cl: Confidence inteval & & &
\end{tabular}


Table 2: Gender-wise distribution of the biochemical parameters in metabolic syndrome and nonmetabolic syndrome individuals (mean \pm SD)

\begin{tabular}{|c|c|c|}
\hline Age (years) & Male & Female \\
\hline Nonmetabolic syndrome & $50.1 \pm 14.1$ & $45.9 \pm 14.4$ \\
\hline Metabolic syndrome & $55.0 \pm 13.3$ & $52.6 \pm 13.8$ \\
\hline \multicolumn{3}{|l|}{$\mathrm{CHO}(\mathrm{mg} / \mathrm{dl})$} \\
\hline Nonmetabolic syndrome & $203.0 \pm 42.5$ & $189.1 \pm 43.3$ \\
\hline Metabolic syndrome & $228.0 \pm 62.0$ & $211.4 \pm 45.5$ \\
\hline \multicolumn{3}{|l|}{$T G(m g / d l)$} \\
\hline Nonmetabolic syndrome & $159.2 \pm 59.2$ & $137.8 \pm 54.5$ \\
\hline Metabolic syndrome & $215.1 \pm 82.0$ & $185.6 \pm 59.0$ \\
\hline \multicolumn{3}{|l|}{$H D L(m g / d l)$} \\
\hline Nonmetabolic syndrome & $45.4 \pm 8.5$ & $46.5 \pm 10.3$ \\
\hline Metabolic syndrome & $38.0 \pm 8.5$ & $40.6 \pm 8.7$ \\
\hline \multicolumn{3}{|l|}{$L D L(m g / d l)$} \\
\hline Nonmetabolic syndrome & $152.4 \pm 45.4$ & $139.4 \pm 41.6$ \\
\hline Metabolic syndrome & $164.8 \pm 57.3$ & $152.6 \pm 44.0$ \\
\hline \multicolumn{3}{|l|}{$V L D L(m g / d l)$} \\
\hline Nonmetabolic syndrome & $32.1 \pm 13.1$ & $28.2 \pm 18.3$ \\
\hline Metabolic syndrome & $44.0 \pm 19.8$ & $37.0 \pm 12.0$ \\
\hline \multicolumn{3}{|l|}{$S B P(m m ~ H g)$} \\
\hline Nonmetabolic syndrome & $125.0 \pm 11.1$ & $122.5 \pm 11.6$ \\
\hline Metabolic syndrome & $136.2 \pm 14.0$ & $130.3 \pm 14.3$ \\
\hline \multicolumn{3}{|l|}{$D B P(m m ~ H g)$} \\
\hline Nonmetabolic syndrome & $83.0 \pm 7.7$ & $81.2 \pm 8.3$ \\
\hline Metabolic syndrome & $89.5 \pm 10.3$ & $86.9 \pm 9.4$ \\
\hline \multicolumn{3}{|l|}{$B M I$} \\
\hline Nonmetabolic syndrome & $26.2 \pm 5.2$ & $25.4 \pm 5.0$ \\
\hline Metabolic syndrome & $27.8 \pm 5.4$ & $27.2 \pm 5.4$ \\
\hline \multicolumn{3}{|l|}{$W C(\mathrm{~cm})$} \\
\hline Nonmetabolic syndrome & $84.7 \pm 13.3$ & $81.8 \pm 13.5$ \\
\hline Metabolic syndrome & $89.2 \pm 14.3$ & $87.7 \pm 12.7$ \\
\hline \multicolumn{3}{|l|}{$H C(\mathrm{~cm})$} \\
\hline Nonmetabolic syndrome & $98.5 \pm 13.0$ & $98.0 \pm 13.0$ \\
\hline Metabolic syndrome & $97.9 \pm 12.3$ & $97.8 \pm 13.6$ \\
\hline \multicolumn{3}{|l|}{ WHR } \\
\hline Nonmetabolic syndrome & $0.87 \pm 0.2$ & $0.85 \pm 0.2$ \\
\hline Metabolic syndrome & $0.93 \pm 0.2$ & $0.91 \pm 0.2$ \\
\hline
\end{tabular}

BMI: Body mass index; CHO: Cholesterol; DBP: Diastolic blood pressure; HC: Hip circumference; HDL: High-density lipoprotein; LDL: Low-density lipoprotein; SBP: Systolic blood pressure; SD: Standard deviation; TG: Triglyceride; VLDL: Very low-density lipoprotein; WC: Waist circumferences; WHR: Waist to hip ratio parameters. Table 3 shows the gender-wise prevalence of metabolic syndrome across different age groups. The study also shows significantly higher rates of MS in the older age groups. The T2DM rates increase from 13.3\% in the age group of 20 to 29 years peaking to $42.8 \%$ in the age group of $60+$ years.

Chi-square outputs of significant proportions with several clinical, demographic and biochemical parameters available to the present study comparing the subjects with and without MS are shown in Table 4. Proportionately, more subjects with MS had type 2 diabetes mellitus (49.4\%). Likewise proportionately more subjects, $81.5 \%$ had hypertrigylerdemia, $81.8 \%$ had low HDL levels, $58.9 \%$ had hypercholesterolemia and $60.1 \%$ suffered from hypertension.

Detailed correlates of MS in univariate analysis and multivariate logistic regression method showing significant predictors of MS are summarized in Table 4. Advancing age, gender, BMI and hypercholesterolemia significantly contributed to the increased MS risk.

Those with low HDL levels have double the risk of developing T2DM as compared to the individuals who with advancing age, the risk of developing MS increases 4.7 times more in 60+ age group than 20 to 29 years age group. Similarly, the increased serum cholesterol levels increased the risk of developing MS two times more. The subjects falling in the obese category have two and half times more risk of developing MS.

Older age, female sex, general obesity and hypercholesterolemia significantly contributed to an increased MS risk among this urban population.

Very few subjects in this study were in the category of health BMI. From Table 5, we infer that only 32.6\% $(\mathrm{n}=355)$ of the subjects presented with a healthy BMI as per the $\mathrm{WHO}$ guidelines. $6.7 \%(\mathrm{n}=73)$ were reported underweight, whereas $36.7 \%(\mathrm{n}=400)$ were reported as preobese and $24 \%(n=261)$ presented as obese. The subject population presented a picture of general obesity as central obesity was not significantly present in this

Table 3: Age-specific and age-standardized prevalence of metabolic syndrome gender-wise in percentage with 95\% confidence interval

\begin{tabular}{|c|c|c|c|c|c|c|}
\hline \multirow[b]{3}{*}{ Age group (years) } & \multicolumn{6}{|c|}{ Prevalence of MS in percentage with $95 \% \mathrm{Cl}$} \\
\hline & \multicolumn{2}{|c|}{ Male } & \multicolumn{2}{|c|}{ Female } & \multicolumn{2}{|c|}{ Total } \\
\hline & $n$ & $\begin{array}{l}\text { Prevalence in percentage } \\
\text { with } 95 \% \mathrm{Cl}\end{array}$ & $n$ & $\begin{array}{l}\text { Prevalence in percentage } \\
\text { with } 95 \% \mathrm{Cl}\end{array}$ & $n$ & $\begin{array}{l}\text { Prevalence in percentage } \\
\text { with } 95 \% \mathrm{Cl}\end{array}$ \\
\hline $20-29$ & 30 & $6.7(-2.8,16.1)$ & 45 & $17.8(6.2,29.4)$ & 75 & $13.3(5.4,21.2)$ \\
\hline $30-39$ & 96 & $17.8(9.9,25.5)$ & 96 & $27.1(18.0,36.1)$ & 192 & $22.4(16.4,28.3)$ \\
\hline $40-49$ & 136 & $27.2(19.6,34.8)$ & 127 & $40.1(31.5,48.8)$ & 263 & $33.5(27.8,39.2)$ \\
\hline $50-59$ & 147 & $30.6(23.1,38.1)$ & 104 & $53.8(44.1,63.6)$ & 251 & $40.2(34.1,46.3)$ \\
\hline $60+$ & 178 & $36.5(29.4,43.7)$ & 130 & $51.5(42.9,60.2)$ & 308 & $42.8(37.3,48.4)$ \\
\hline Total & 587 & $28.2(24.6,31.9)$ & 502 & $41.4(37.1,45.7)$ & 1089 & $34.3(31.5,37.1)$ \\
\hline
\end{tabular}

$\mathrm{Cl}$ : Confidence interval 
Table 4: Risk factors for metabolic syndrome

\begin{tabular}{|c|c|c|c|c|c|}
\hline \multirow{2}{*}{$\begin{array}{l}\text { Variables } \\
\text { Age (years) }\end{array}$} & \multirow[t]{2}{*}{$\begin{array}{l}\text { Metabolic syndrome } \\
\text { nonmetabolic syndrome } \\
n(\% \text { age) }\end{array}$} & \multirow[t]{2}{*}{$\begin{array}{l}p \text {-value } \\
\text { metabolic syndrome } \\
n(\% \text { age })\end{array}$} & \multirow[t]{2}{*}{$\begin{array}{l}\text { Unadjusted Odds ratio } \\
\text { with } 95 \% \mathrm{Cl}\end{array}$} & \multicolumn{2}{|l|}{$\begin{array}{l}\text { Adjusted Odds ratio } \\
\text { with } 95 \% \mathrm{Cl}\end{array}$} \\
\hline & & & & & \\
\hline $20-29$ & $65(9.0)$ & $10(2.6)$ & $<0.00$ & 1.0 & 1.0 \\
\hline $30-39$ & $149(20.8)$ & $43(11.5)$ & & $1.9(0.9,4.0)$ & $1.9(0.8,4.0)$ \\
\hline $40-49$ & $175(24.4)$ & $88(23.5)$ & & $3.3(1.6,6.7)$ & $3.0(1.4,6.4)$ \\
\hline $50-59$ & $150(20.9)$ & $101(27.0)$ & & $4.4(2.1,8.9)$ & $4.3(2.0,9.0)$ \\
\hline $60+$ & $176(24.6)$ & $132(35.2)$ & & $4.9(2.4,9.9)$ & $4.7(2.3,9.8)$ \\
\hline \multicolumn{6}{|l|}{ Gender } \\
\hline Female & $294(41.1)$ & $208(55.6)$ & $<0.00$ & 1.0 & 1.0 \\
\hline Male & $421(58.8)$ & $166(44.3)$ & & $0.5(0.4,0.7)$ & $0.5(0.3,0.6)$ \\
\hline \multicolumn{6}{|l|}{$B M I$} \\
\hline Underweight & $262(36.6)$ & $93(24.8)$ & $<0.00$ & $1.1(0.6,2.0)$ & $1.2(0.6,2.0)$ \\
\hline Normal & $52(7.2)$ & $21(5.6)$ & & 1.0 & 1.0 \\
\hline Preobese & $255(35.6)$ & $145(38.7)$ & & $1.6(1.2,2.2)$ & $1.6(1.2,2.3)$ \\
\hline Obese & $146(20.4)$ & $115(30.7)$ & & $2.2(1.6,3.1)$ & $2.6(1.8,3.7)$ \\
\hline \multicolumn{6}{|l|}{ Waist circumference } \\
\hline$<102 \mathrm{~cm}$ in males & $592(82.8)$ & $206(55.0)$ & $<0.00$ & 1.0 & - \\
\hline \multicolumn{6}{|l|}{$<88 \mathrm{~cm}$ in females } \\
\hline$\geq 102 \mathrm{~cm}$ in males & $123(17.2)$ & $168(44.9)$ & & $3.9(3.0,5.2)$ & - \\
\hline \multicolumn{6}{|l|}{$\geq 88 \mathrm{~cm}$ in females } \\
\hline \multicolumn{6}{|l|}{ Physical activity } \\
\hline Mild & $28(3.9)$ & $17(4.5)$ & 0.64 & 1.0 & - \\
\hline Moderate & $77(10.7)$ & $46(12.3)$ & & $1.0(0.5,2.0)$ & - \\
\hline Heavy & $610(85.3)$ & $311(83.1)$ & & $0.8(0.4,1.5)$ & - \\
\hline \multicolumn{6}{|l|}{ Diet } \\
\hline Vegetarian & $382(53.4)$ & $194(51.8)$ & 0.62 & 1.0 & - \\
\hline Nonvegetarian & $333(46.5)$ & $180(48.1)$ & & $1.0(0.8,1.4)$ & - \\
\hline \multicolumn{6}{|l|}{ Alcohol intake } \\
\hline Nonalcoholic & $552(77.2)$ & $308(82.3)$ & 0.04 & 1.0 & - \\
\hline Alcoholic & $163(22.8)$ & $66(17.6)$ & & $0.7(0.5,1.0)$ & - \\
\hline \multicolumn{6}{|l|}{ Family history } \\
\hline No family history & $406(56.7)$ & $199(53.2)$ & 0.40 & 1.0 & - \\
\hline Family history of T2DM & $166(23.2)$ & $88(23.5)$ & & $1.1(0.8,1.0)$ & - \\
\hline $\begin{array}{l}\text { Family history of } \\
\text { hypertension }\end{array}$ & $143(20.0)$ & $87(23.2)$ & & $1.2(0.9,1.7)$ & - \\
\hline \multicolumn{6}{|l|}{ Type of oil used } \\
\hline Refined & $507(70.9)$ & $254(67.9)$ & 0.28 & 1.0 & - \\
\hline Desi Ghee & $125(17.4)$ & $64(17.1)$ & & $1.0(0.7,1.4)$ & - \\
\hline Dalda & $83(11.6)$ & $56(14.9)$ & & $1.3(0.9,1.9)$ & - \\
\hline \multicolumn{6}{|l|}{ Triglycerides } \\
\hline$<150 \mathrm{mg} / \mathrm{dl}$ & $416(58.1)$ & $69(18.4)$ & $<0.00$ & 1.0 & - \\
\hline$\geq 150 \mathrm{mg} / \mathrm{dl}$ & $299(41.8)$ & $305(81.5)$ & & $6.1(4.5,8.3)$ & - \\
\hline \multicolumn{6}{|l|}{$H D L$} \\
\hline$<40 \mathrm{mg} / \mathrm{dl}$ for males & $294(41.1)$ & $306(81.8)$ & $<0.00$ & 1.0 & - \\
\hline$<50 \mathrm{mg} / \mathrm{dl}$ for females & & & & & \\
\hline$\geq 40 \mathrm{mg} / \mathrm{dl}$ for males & $421(58.9)$ & $68(18.1)$ & & $6.4(4.8,8.7)$ & - \\
\hline$\geq 50 \mathrm{mg} / \mathrm{dl}$ for females & & & & & \\
\hline Cholesterol & & & & & \\
\hline$<200 \mathrm{mg} / \mathrm{dl}$ & $421(58.9)$ & $154(41.2)$ & $<0.00$ & 1.0 & 1.0 \\
\hline$\geq 200 \mathrm{mg} / \mathrm{dl}$ & $294(41.1)$ & $220(58.9)$ & & $2.0(1.6,2.6)$ & $1.9(1.5,2.5)$ \\
\hline$L D L$ & & & & & \\
\hline$<130 \mathrm{mg} / \mathrm{dl}$ & $244(34.1)$ & $115(30.7)$ & 0.26 & 1.0 & - \\
\hline$\geq 130 \mathrm{mg} / \mathrm{dl}$ & $471(65.8)$ & $259(69.2)$ & & $1.2(0.9,1.5)$ & - \\
\hline Diabetes & & & & & \\
\hline Not present & $647(90.4)$ & $189(50.5)$ & $<0.00$ & 1.0 & - \\
\hline Present & $68(9.5)$ & $185(49.4)$ & & $9.3(6.8,12.9)$ & - \\
\hline Hypertension & & & & & \\
\hline Not present & $549(76.7)$ & $149(39.8)$ & $<0.00$ & 1.0 & - \\
\hline Present & $166(23.2)$ & $225(60.1)$ & & $5.0(3.9,6.5)$ & - \\
\hline
\end{tabular}


Table 5: BMI: WHR distribution in the sample population

\begin{tabular}{lll}
\hline BMI & WHR & $N$ \\
\hline Normal & $0.79 \pm 0.15$ & 355 \\
Underweight & $0.71 \pm 0.2$ & 73 \\
Preobese & $0.91 \pm 0.18$ & 400 \\
Obese & $1.01 \pm 0.2$ & 261 \\
\hline
\end{tabular}

BMI: Body mass index; WHR:

population. General obesity is related to the abnormal lipid profile values, i.e. increased serum cholesterol, serum triglyride, LDL and decreased HDL values.

From Tables 6 and 7, we infer that out of 1089 subjects there were only 84 subjects who reported with not a single abnormal component of the MS. The rest 1005 subjects had either one or more component abnormal in them. Table 8 indicates the age-wise distribution of MS in the Urban Sikh population of Amritsar.

\section{DISCUSSION}

The overall prevalence of MS in Urban Sikh population of Amritsar was 34.3\% with a higher prevalence among women $(41.4 \%)$ compared with men $(28.2 \%)$. We also found that the prevalence of MS increases with age in both sexes (Fig. 1). It is noteworthy, that $13.3 \%$ of subjects in the age group of 20 to 29 years had MS. The higher prevalence of MS in younger age in Punjabi Sikhs is of particular concern, as it implies that they might have a more prolonged exposure to atherosclerotic risk factors associated with MS.

The prevalence of MS is increasing exponentially in India, both in the urban and rural areas. It has escalated in different parts of India to figures now ranging from 11 to $41 \%{ }^{16}$

Earlier studies across Urban India documented prevalences ranging from 22.1 to $41 \%,{ }^{17-19}$ which is comparable with our observation of $34.3 \%$. Likewise, a prevalence study of urban community in northern India reported a prevalence of $22.37 \%$ for MS. ${ }^{20}$ On the contrary, a lower prevalence of $19.52 \%$ was reported in an Urban popula- tion in western India. ${ }^{21}$ While these studies show high prevalence of MS in Asian Indians living in India, truly representative data from all regions of India are not available. ${ }^{6,22}$

Furthermore, Asian Indians are metabolically obese but physically nonobese. ${ }^{23,24}$ In our study even with modified BMI cut-off values for South Asians, $60.6 \%$ of subjects did not have general obesity, but still had MS. For any given level of BMI, Asian Indians had been recognized to have increased prevalence of cardiometabolic abnormalities as compared to other ethnic groups. ${ }^{25,26}$

Asian Indians are a high risk population with respect to diabetes and CVD, and the numbers are consistently on the rise. ${ }^{27}$ The prevalence of MS in Asian Indians varies according to the region, the extent of urbanization, lifestyle patterns, and socioeconomic/cultural factors. Recent data show that about one third of the Urban population in India's major cities have MS. ${ }^{28}$ The prevalence of MS in our study in females was 2 times higher as compared to females, as in other studies in India, MS prevalence in women was 1.5 to 2 times higher than in males. ${ }^{29,30}$ A higher prevalence in women might be related to their higher rates of overweight BMI, impaired blood glucose levels, high TG, and low levels of HDL-C. Chow et al ${ }^{31}$ found a prevalence of MS of $26.9 \%$ in males and $18.4 \%$ in females in southern India.

The development of obesity, or more specifically an increase in abdominal fat, is thought to be the primary event in the progression of MS. A tendency to gain fat in the abdominal area, as opposed to the hip, buttock, and limb areas, is linked to a rise in fatty acids in the blood, which is thought to lead to insulin resistance, high blood pressure, abdominal blood lipids and eventually diabetes. Asian Indians tend to develop central obesity rather than generalized obesity. About three fourth of the subjects participated in study were overweight/obese $\left(\mathrm{BMI} \geq 23 \mathrm{~kg} / \mathrm{m}^{2}\right)$, being a prime determinant of MS prevalence. Of these around one third of overweight/obese subjects had impaired glucose tolerance and many exhibit features of MS.

Table 6: Age-wise and gender-wise distribution of number of individuals with abnormal findings in the various components of metabolic syndrome

\begin{tabular}{|c|c|c|c|c|c|c|c|c|c|c|}
\hline \multirow{3}{*}{$\begin{array}{l}\text { Age } \\
\text { group } \\
\text { (years) }\end{array}$} & \multicolumn{10}{|c|}{ Components of MS } \\
\hline & $\begin{array}{l}\text { Waist circum- } \\
\text { ference } \geq 102 \mathrm{~cm} \\
\text { in males } \geq 88 \mathrm{~cm} \\
\text { in females }\end{array}$ & & $\begin{array}{l}\text { Triglyceri } \\
\geq 150 \mathrm{mg}\end{array}$ & & $\begin{array}{l}H D L \\
<40 \mathrm{mg} / \\
\text { males }< \\
\text { for femal }\end{array}$ & & $\begin{array}{l}B P \geq 135 \\
85 \mathrm{~mm} \mathrm{H}\end{array}$ & & $\begin{array}{l}\text { Fasting } \\
\text { Blood sus } \\
>110 \mathrm{mg}\end{array}$ & \\
\hline & Females & Males & Females & Males & Females & Males & Females & Males & Females & Males \\
\hline $20-29$ & 19 & 6 & 13 & 10 & 31 & 14 & 5 & 3 & 7 & 5 \\
\hline $30-39$ & 41 & 14 & 32 & 49 & 72 & 29 & 17 & 26 & 17 & 20 \\
\hline $40-49$ & 63 & 25 & 63 & 83 & 97 & 45 & 36 & 57 & 37 & 44 \\
\hline 50-59 & 40 & 10 & 67 & 98 & 84 & 57 & 48 & 66 & 41 & 62 \\
\hline$>60$ & 51 & 22 & 75 & 114 & 103 & 68 & 63 & 107 & 57 & 72 \\
\hline
\end{tabular}

BP: Blood pressure; HDL: High-density lipoprotein; MS: Metabolic syndrome 
Table 7: Number of components of metabolic syndrome found to be positive in the subject population

\begin{tabular}{lll}
\hline $\begin{array}{l}\text { Number of } \\
\text { components positive }\end{array}$ & Frequency & $\begin{array}{l}\text { Percentage } \\
(\%)\end{array}$ \\
\hline 0 & 84 & 7.7 \\
1 & 255 & 23.4 \\
$>2$ & 376 & 34.5 \\
$>3$ & 238 & 21.8 \\
$>4$ & 116 & 10.7 \\
$>5$ & 20 & 1.8 \\
\hline
\end{tabular}

Table 8: Age-wise: metabolic syndrome distribution

\begin{tabular}{llll}
\hline Total age groups & Non-MS & MS & Total \\
\hline $20-29$ & 65 & 10 & 75 \\
$30-39$ & 149 & 43 & 192 \\
$40-49$ & 175 & 88 & 263 \\
$50-59$ & 150 & 101 & 251 \\
$60+$ & 176 & 132 & 308 \\
\hline Total & 715 & 374 & 1089 \\
\hline
\end{tabular}

MS: Metabolic syndrome

In our study, we observed approximately $23.5 \%$ of subjects had history of type 2 diabetes. This means that the remaining subjects with impaired blood glucose levels were on their way to risk of developing type 2 diabetes, which is an important risk factor for CAD. Enas et $\mathrm{al}^{32}$ in Coronary Artery Disease in Indians (CADI) study report the prevalence of diabetes to be 3 to 6 times higher among South Asians than Europeans, Americans, and other Asians. In India, it is estimated that 32 million people suffer from diabetes, and the number is projected to increase to 69.8 million by $2025 .{ }^{27}$

Increased prevalence of low HDL-C has been reported earlier by Enas et a ${ }^{32}$ who found that only $4 \%$ of Asian Indian men and 5\% Asian Indian women had optimal HDL-C levels. Low HDL-C levels are a strong predictor of occurrence and reoccurrence of myocardial infract (MI) and stroke and are associated with premature and severe CAD. Approximately half of the population had low levels of HDL-C of which $23 \%$ were from 20 to 40 age group that is, the young adults. Similar findings were also reported by Sawant et $\mathrm{al}^{33}$ a recent study on 9000 subjects $(<40$ years of age) attending the Health Check program at PD Hinduja National Hospital, it was shown that around $64.2 \%$ men and $33.8 \%$ women had abnormally

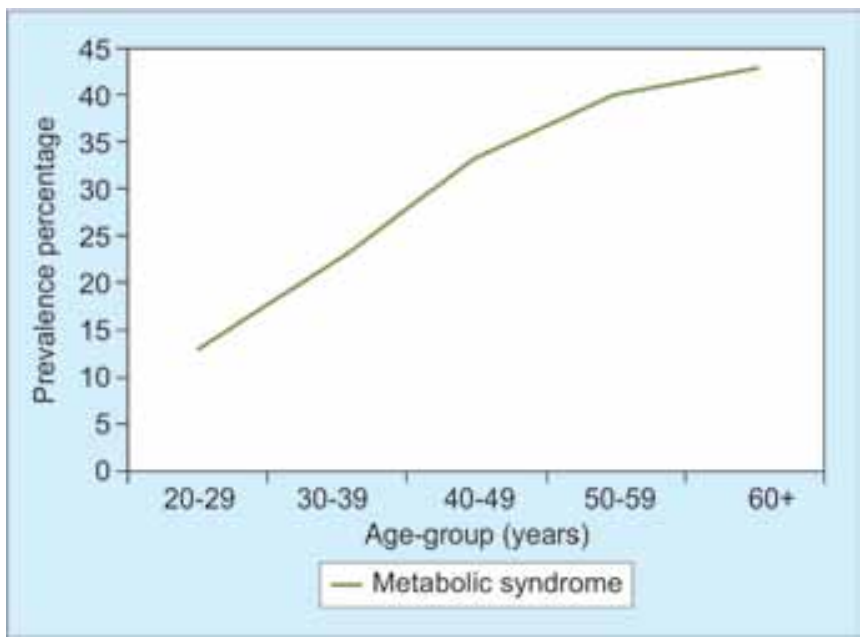

Fig. 1: Age-wise trend of metabolic syndrome

low levels of HDL-C. Obesity reduces HDL-C levels, and obese patients with MS and atherogenic dyslipidemia almost always have low HDL-C levels. Our study shows that around $35 \%$ of subjects had low HDL-C were either overweight or obese.

Our study clearly indicates that the Young Sikh adults $<40$ years of age have similar high BMI, WC and WHR to that of the older adults $>40$ years of age (Table 9).

The fact that 1005 out of 1089 subjects had one or more component abnormal clearly indicates that this particular section of the population is highly predisposed to the development of the metabolic syndrome at some stage of their lifetime. The development of these disorders is related to the increased risk of developing atherosclerotic changes in the body leading to the development of cardiovascular disorders and type- 2 diabetes. Central obesity and insulin resistance are thought to represent common underlying factors of the syndrome. ${ }^{34}$ Atherosclerosis is the underlying process of a majority of cardiovascular disease and mortality. While the clinical manifestations of atherosclerosis usually do not occur until middle age, atherosclerosis develops early in life. Several studies have shown associations between MetS and increased risk of cardiovascular disease (CVD). ${ }^{35-40}$

It is necessary to adopt appropriate preventive strategies and interventions in high-risk individuals to curb the growing epidemic of MS.

Table 9: Mean and standard deviation values of the anthropometric physiological and biochemical parameters accordingly to age group

\begin{tabular}{llllll}
\hline Age (years) & $B M I$ & Waist & WHR & TG & CHO \\
\hline $0-40$ & $26.4 \pm 5.3$ & $85.7 \pm 13.5$ & $0.89 \pm 0.19$ & $150.7 \pm 66.1$ & $188.8 \pm 46.2$ \\
$>40$ & $26.3 \pm 5.3$ & $84.9 \pm 13.7$ & $0.88 \pm 0.20$ & $173.3 \pm 66.5$ & $210.8 \pm 47.8$ \\
Age (years) & $H D L$ & $L D L$ & $V L D L$ & $S B P$ & $D B P$ \\
$0-40$ & $44.4 \pm 10.3$ & $135.4 \pm 42.6$ & $31.1 \pm 11.5$ & $121.3 \pm 11.5$ & $80.5 \pm 8.1$ \\
$>40$ & $43.4 \pm 9.3$ & $156.8 \pm 14.6$ & $34.8 \pm 14.6$ & $129.2 \pm 13.2$ & $85.7 \pm 9.0$ \\
\hline
\end{tabular}

BMI: Body mass index; CHO: Cholesterol; TG: Triglycerides; WHR: Waist to hip ratio 


\section{CONCLUSION}

The study showed high prevalence of MS in the Urban Sikh population of Amritsar. It was found that there were only 84 subjects out of sample size of 1089 which were completely normal. The rest 1005 subjects had either one or more abnormal component of the MS as classified by the WHO. This fact needs serious preventive measures to curb this disease as it is the major factor leading to the cardiovascular disorders in this section of the population.

\section{FUNDING SUPPORT}

The study was conducted under the project sanctioned by the University Grants Commission as Minor research project entitled: Evaluation of the Prevalence of type 2 diabetes mellitus, hypertension and MS and awareness of its risk factors in the Urban Punjabi Sikh population for the period 2013 to 2015.

\section{REFERENCES}

1. Grundy SM. Metabolic syndrome: connecting and reconciling cardiovascular and diabetes worlds. J Am Coll Cardiol 2006;47:1093-1100.

2. Enas EA, Mohan V, Deepa M, Farooq S, Pazhoor S, Chennikkara $\mathrm{H}$. The metabolic syndrome and dyslipidemia among Asian Indians: a population with high rates of diabetes and premature coronary artery disease. J Cardiometabolic Syndrome 2007;2(4):267-275.

3. Nestel P, Lyu R, Lip PL, et al. Metabolic syndrome: recent prevalence in East and Southeast Asian populations. Asia Pacific J Clin Nutrit 2007;16(2):362-367.

4. Eapen D, Kalra GL, Merchant N, Arora A, Khan BV. Metabolic syndrome and cardiovascular disease in South Asians. Vascular Health and Risk Management 2009;5:731-743.

5. Enas EA, Kannan S, editors. How to beat the heart disease epidemic among South Asians. 1st ed. Downers Grove, IL: Advanced Heart Lipid Clinic 2008. The Pediatric Foundations of Heart Disease, p. 153-160.

6. Misra A, Khurana L. The metabolic syndrome in South Asians: epidemiology, clinical correlates and possible solutions. Int Diabetes Monitor 2009;21:92-101.

7. Misra A, Misra R, Wijesuriya M, Banerjee D. The metabolic syndrome in South Asians: continuing escalation and possible solutions. Indian J Med Res 2007;125:345-354.

8. Prasad DS, Kabir Z, Dash AK, Das BC. Abdominal obesity, an independent cardiovascular risk factor in Indian subcontinent: a clinico epidemiological evidence summary. J Cardiovasc Dis Res 2011;2:199-205.

9. Prasad DS, Kabir Z, Dash AK, Das BC. Childhood cardiovascular risk factors in South Asians: a cause of concern for adult cardiovascular disease epidemic. Ann Pediatr Cardiol 2011;4:166-171.

10. Anjana RM, Ali MK, Pradeepa R, Deepa M, Datta M, Unnikrishnan $\mathrm{R}$, et al. The need for obtaining accurate nationwide estimates of diabetes prevalence in IndiaRationale for a national study on diabetes. Indian J Med Res 2011 Apr;133:369-380.
11. Shah B, Mathur P. Surveillance of cardiovascular disease risk factors in India: The need and scope. Indian J Med Res 2010 Nov;132:634-642.

12. Goenka S, Prabhakaran D, Ajay VS, Reddy KS. Preventing cardiovascular disease in India: translating evidence, to action. Current Sci 2009;97(3):367-377.

13. Reddy KS, Prabhakaran D, Chaturvedi V, et al. Methods for establishing a surveillance system for cardiovascular diseases in Indian industrial populations. Bulletin of the World Health Organization 2006;84(6):461-469.

14. Sidhu S, Kumari K, Prabhjot. Sociodemographic variables of hypertension among adult Punjabi females. J Hum Ecol 2005;17(3):211-215.

15. Alberti KG, Zimmet P, Shaw J. Metabolic syndrome: a new world-wide definition. A consensus statement from the International Diabetes Federation. Diabet Med 2006 May;23(5):469-480.

16. Misra A, Khurana L. Obesity and the metabolic syndrome in developing countries. J Clin Endocrinol Metab 2008 Nov; 93(11 Suppl 1):s9-30.

17. Tharkar S, Viswanathan V. Effect of obesity on cardiovascular risk factors in urban population in South India. Heart Asia 2010;2:145-149.

18. Vasan SK, Thomas N, Christopher S, Geethanjali FS, Paul TV, Sanjeevi CB. Anthropometric measurements for the prediction of the metabolic syndrome: a cross-sectional study on adolescents and young adults from southern India. Heart Asia 2011;3:2-7.

19. Ramachandran A, Snehalatha C, Satyavani K, Sivasankari S, Vijay V. Metabolic syndrome in urban Asian Indian adults: a population study using modified ATPIII criteria. Diabetes Res Clin Pract 2003;60:199-204.

20. Ravikiran M, Bhansali A, Ravikumar P, Bhansali S, Dutta $P$, Thakur JS, et al. Prevalence and risk factors of metabolic syndrome among Asian Indians: a community survey. Diabetes Res Clin Pract 2010;8:269-273.

21. Sawant A, Mankeshwar R, Shah S, Raghavan R, Dhongde G, Raje $\mathrm{H}$, et al. Prevalence of metabolic syndrome in Urban India. Cholesterol 2011;2011:920983.

22. Mohan V, Rao GHR. Type 2 diabetes in South Asains. 1st ed. New Delhi: South Asian Society on Atherosclerosis and Thrombosis; 2007.

23. Ruderman N, Chisholm D, Pi-Sunyer X, Schneider S. The metabolically obese, normal-weight individual revisited. Diabetes 1998;47:699-713.

24. Manoria PC, Manoria P, Manoria P. Metabolic obesity: a new therapeutic target for cardiometabolic risk reduction. CVD Prev Control 2010;5:39-44.

25. Deurenberg P, Deurenberg-Yap M, Guricci S. Asians are different from caucasians and from each other in their body mass index/body fat per cent relationship. Obes Rev 2002;3:141-146.

26. Tan CE, Ma S, Wai D, Chew SK, Tai ES. Can we apply the National cholesterol education program adult treatment panel definition of the metabolic syndrome to Asians? Diabetes Care 2004;27:1182-1186.

27. Enas EA, Chacko V, Pazhoor SG, Chennikkara H, Devarapalli HP. Dyslipidemia in South Asian patients. Current Atherosclerosis Reports, 2007;9(5):367-374.

28. Misra A, Khurana L. The metabolic syndrome in South Asians: epidemiology, clinical correlates and possible solutions. Int Diabetes Monitor 2009;21(3):92-101. 
29. Prabhakaran D, Chaturvedi V, Shah $\mathrm{P}$, et al. Differences in the prevalence of metabolic syndrome in Urban and rural India: a problem of urbanization. Chronic Illness 2007;3(1):8-19.

30. Misra A, Khurana L. The metabolic syndrome in South Asians: epidemiology, determinants and prevention. Metabolic Syndrome and Related Disorders 2009;7(6):497-514.

31. Chow CK, Naidu S, Raju K, et al. Significant lipid, adiposity and metabolic abnormalities amongst 4535 Indians from a developing region of rural Andhra Pradesh. Atherosclerosis 2008;196(2):943-952.

32. Enas EA, Yusuf S, Mehta JL. Prevalence of coronary artery disease in Asian Indians. Am J Cardiol 1992;70(9):945-949.

33. Sawant AM, Shetty D, Mankeshwar R, Ashavaid TF. Prevalence of dyslipidemia in young adult Indian population. J Assoc Physicians of India 2008;56:99-102.

34. Paoletti R, Bolego C, Poli A, Cignarella A. Metabolic syndrome, inflammation and atherosclerosis. Vasc Health Risk Manag 2006 Jun;2(2):145-152.

35. Lakka HM, Laaksonen DE, Lakka TA, Niskanen LK, Kumpusalo E, Tuomilehto J, Salonen JT. The metabolic syndrome and total and cardiovascular disease mortality in middle-aged men. JAMA 2002;288(21):2709-2716.

36. Sipila K, Moilanen L, Nieminen T, Reunanen A, Jula A, Salomaa V, Kaaja R, Kukkonen-Harjula K, Lehtimaki T, Kesaniemi YA, et al. Metabolic syndrome and carotid intima media thickness in the Health 2000 Survey. Atherosclerosis 2009;204(1):276-281.

37. Eckel RH, Alberti KG, Grundy SM, Zimmet PZ. Lancet. The metabolic syndrome 2010 Jan 16;375(9710):181-183.

38. Guize L, Pannier B, Thomas F, Bean K, Jego B, Benetos A. Recent advances in metabolic syndrome and cardiovascular disease. Arch Cardiovasc Dis 2008;101(9):577-583.

39. Iglseder B, Cip P, Malaimare L, Ladurner G, Paulweber B. The metabolic syndrome is a stronger risk factor for early carotid atherosclerosis in women than in men. Stroke 2005;36(6): 1212-1217.

40. Galassi A, Reynolds K, He J. Metabolic syndrome and risk of cardiovascular disease: a meta-analysis. Am J Med 2006 Oct;119(10):812-819. 